University of Nebraska - Lincoln

DigitalCommons@University of Nebraska - Lincoln

\title{
Genetic analysis of Trichinella populations by 'cold' single-strand conformation polymorphism analysis
}

Robin B. Gasser

The University of Melbourne \& Macquarie University, robinbg@unimelb.edu.au

Min $\mathrm{Hu}$

The University of Melbourne

Youssef Abs EL-Osta

The University of Melbourne

Dante S. Zarlenga

US Department of Agriculture, ARS, Bovine Functional Genomics Laboratory

Edoardo Pozio

Parasitic and Immunomediated Diseases, Istituto Superiore di Sanita

Follow this and additional works at: https://digitalcommons.unl.edu/usdaarsfacpub

Gasser, Robin B.; Hu, Min; EL-Osta, Youssef Abs; Zarlenga, Dante S.; and Pozio, Edoardo, "Genetic analysis of Trichinella populations by 'cold' single-strand conformation polymorphism analysis" (2005).

Publications from USDA-ARS / UNL Faculty. 2233.

https://digitalcommons.unl.edu/usdaarsfacpub/2233

This Article is brought to you for free and open access by the U.S. Department of Agriculture: Agricultural Research Service, Lincoln, Nebraska at DigitalCommons@University of Nebraska - Lincoln. It has been accepted for inclusion in Publications from USDA-ARS / UNL Faculty by an authorized administrator of DigitalCommons@University of Nebraska - Lincoln. 


\title{
Genetic analysis of Trichinella populations by 'cold' single-strand conformation polymorphism analysis
}

\author{
Robin B. Gasser ${ }^{\mathrm{a}, \mathrm{b}, *}$, Min $\mathrm{Hu}^{\mathrm{a}}$, Youssef Abs EL-Osta ${ }^{\mathrm{a}}$, \\ Dante S. Zarlenga ${ }^{\mathrm{c}}$, Edoardo Pozio ${ }^{\mathrm{d}}$ \\ ${ }^{\text {a }}$ Department of Veterinary Science, The University of Melbourne, 250 Princes Highway, Werribee, Victoria 3030, Australia \\ ${ }^{\mathrm{b}}$ Biotechnology Research Institute, Macquarie University, Sydney, NSW 2109, Australia \\ ${ }^{\mathrm{c}}$ US Department of Agriculture, ARS, Bovine Functional Genomics Laboratory, Beltsville, Maryland, USA \\ ${ }^{\mathrm{d}}$ Department of Infectious, Parasitic and Immunomediated Diseases, Istituto Superiore di Sanità, Rome, Italy
}

\begin{abstract}
A non-isotopic single-strand conformation polymorphism ('cold' SSCP) technique has been assessed for the analysis of sequence variability in the expansion segment 5 (ES5) of domain IV and the D3 domain of nuclear ribosomal DNA within and/or among isolates and individual muscle (first-stage) larvae representing all currently recognized species/genotypes of Trichinella. Data are consistent with the ability of cold SSCP to identify intra-specific as well as inter-specific variability among Trichinella genotypes. The cold SSCP approach should be applicable to a range of other genetic markers for comparative studies of Trichinella populations globally.

(C) 2005 Elsevier B.V. All rights reserved.
\end{abstract}

Keywords: Trichinella; D3 domain; Expansion segment 5; Genetic variation; Nuclear ribosomal DNA; Single-strand conformation polymorphism

\section{Introduction}

Studying the genetic make up of Trichinella populations is central to investigating transmission patterns and control. Various DNA techniques, such as restriction fragment length polymorphism, DNAhybridization and sequencing of genes of the nuclear or mitochondrial genomes, provide useful comple-

\footnotetext{
* Corresponding author. Tel.: +61397312000; fax: +61 397312366 .

E-mail address: robinbg@unimelb.edu.au (R.B. Gasser).
}

mentary tools for the identification of some species and genotypes and for investigating genetic variation within this genus (reviewed by Zarlenga and La Rosa, 2000; Zarlenga et al., 2004). Polymerase chain reaction (PCR) techniques have been used broadly because of their ability to specifically amplify sequences from individual larvae. For example, Zarlenga et al. (1999, 2001) have established an effective multiplex PCR, employing genetic loci in the expansion segment 5 (ES5) within domain IV and internal transcribed spacers (ITS) of nuclear ribosomal DNA (rDNA). This PCR allows the detection and 
differentiation of most of the recognized species and genotypes of Trichinella based on the sizes of specific amplicons on agarose gels. However, it does not permit the analysis of the nature and extent of sequence variation within and among individual genotypes (i.e., within isolates, and within or among individuals). In contrast, mutation scanning approaches, such as single-strand conformation polymorphism (SSCP; Orita et al., 1989), allow the direct display of sequence variation within and among PCR products. SSCP has been applied to various parasites, including Trichinella, for the purpose of investigating their population genetics and taxonomy (e.g., Gasser et al., 1998; Gasser and Chilton, 2001). Mostly, radiolabelled amplicons (usually $\sim 300-550 \mathrm{bp}$ in size) have been used for SSCP analysis in thin, nondenaturing gel matrices (e.g., mutation detection enhancement, MDE). While this approach has a high-resolution capacity, some disadvantages are the human health risk associated with the use of radioisotopes and the time required for the casting of electrophoretic gels. To overcome these limitations, a simple, non-isotopic SSCP approach was recently established for the analysis of sequence variation in ribosomal DNA loci within and among all of the currently recognized species and genotypes of Trichinella.

\section{Materials and methods}

\subsection{Parasite material and genomic DNA isolation}

Isolates of Trichinella from different geographical origins and hosts were available from the International Trichinella Reference Centre in Rome (Pozio et al., 1989; http://www.trichi.iss.it/). Muscle larvae (L1) from reference strains representing the eight recognized species and the three additional genotypes (Murrell et al., 2000; Pozio et al., 2002) were used for comparative purposes. Reference strains and most other isolates were maintained in CD1 female mice whereas some other isolates originated from naturally infected hosts. First-stage larvae were isolated by pepsin $(1 \%)-\mathrm{HCl}(1 \%)$ digestion at $40{ }^{\circ} \mathrm{C}$ for $30 \mathrm{~min}$, sedimented and washed in physiological saline and then suspended in 90\% ethanol. Genomic DNA (gDNA) from "pooled" L1s was isolated by SDS/proteinase K digestion $\left(37^{\circ} \mathrm{C}\right.$ for $12 \mathrm{~h}$ ) (Gasser et al., 1993), and then purified over a spin column (Wizard ${ }^{\mathrm{TM}}$ DNA CleanUp, Promega) and eluted into $30 \mu \mathrm{l}$ of $\mathrm{H}_{2} \mathrm{O}$.

\subsection{PCR, agarose gel electrophoresis and cold SSCP}

Regions of rDNA were amplified by PCR from gDNA samples. The ES5 was amplified using primers oTsr4 (5'-GTTCCATGTGAACAGCAGT- $\left.3^{\prime}\right)$ and oTsr3 (5'-GCGATTGAGTTGAACGC-3') (Zarlenga et al., 1992), and the D3 domain was amplified using primer NC28-26 (5'-ACCCGTCTTGAAACACGGA$\left.3^{\prime}\right)$ and NC28-25R (5'-GATTAGTCTTTCGCCCCTA$3^{\prime}$ ) (cf. Chilton et al., 2003). Genomic DNA (1.5 $\left.\mu \mathrm{l}\right)$ was added to $48.5 \mu \mathrm{l}$ of PCR mix (overlaid with paraffin oil) containing $250 \mu \mathrm{M}$ of each dNTP, $1.5 \mathrm{mM} \mathrm{MgCl} 2,25 \mathrm{pmol}$ of each primer and $2 \mathrm{U}$ of Taq polymerase (Promega), immediately placed on a freeze block $\left(-20^{\circ} \mathrm{C}\right)$ and then subjected to cycling in a 480 thermocycler (Perkin-Elmer Cetus) at $94{ }^{\circ} \mathrm{C}$, 5 min (initial denaturation), followed by 35 cycles of $94{ }^{\circ} \mathrm{C}, 30 \mathrm{~s}$ (denaturation), $55^{\circ} \mathrm{C}, 30 \mathrm{~s}$ (annealing) and $72{ }^{\circ} \mathrm{C}, 30 \mathrm{~s}$, followed by $72{ }^{\circ} \mathrm{C}$ for $5 \mathrm{~min}$. Samples without DNA (no-DNA) or with mouse DNA were included as controls. After thermocycling, individual amplicons were mixed with an equal volume of loading buffer $(10 \mathrm{mM} \mathrm{NaOH}, 95 \%$ formamide, $0.05 \%$ of both bromophenol blue and xylene cyanole) and the intensity of selected samples verified on ethidium bromide-stained, $2 \%$ agarose gels using TBE (65 mM Tris-HCl, $27 \mathrm{mM}$ boric acid, $1 \mathrm{mM}$ EDTA, pH 9; Bio-Rad, Richmond, CA, USA) as the buffer and ФX174-HaeIII (Promega, WI, USA) as a size marker. After denaturation at $94{ }^{\circ} \mathrm{C}$ for $15 \mathrm{~min}$ and snap cooling on a freeze block $\left(-20^{\circ} \mathrm{C}\right)$, samples $(\sim 12 \mu \mathrm{l})$ were loaded into the wells of precast GMA $^{\text {TM }}$ S-50 gels $(96 \mathrm{~mm} \times 261 \mathrm{~mm}$; product no. 3548, Elchrom Scientific) and subjected to electrophoresis for $14 \mathrm{~h}$ at $72 \mathrm{~V}$ and $7.2{ }^{\circ} \mathrm{C}$ (constant) in a horizontal SEA2000 ${ }^{\mathrm{TM}}$ apparatus (Elchrom Scientific) connected to a MultiTemp III (Pharmacia) cooling system. After electrophoresis, gels were stained for 15 min with ethidium bromide $(0.5 \mu \mathrm{g} / \mathrm{ml})$, destained in water for the same time and then photographed. SSCP profiles were demonstrated to be reproducible on different days using amplicons produced on different days. 


\subsection{Sequencing and analyses}

Selected amplicons were cloned into the pGEM-T Easy ${ }^{\mathrm{TM}}$ plasmid vector (Promega) and sequenced using the vector primers SP6 and T7 (Promega). The $5^{\prime}$ - and $3^{\prime}$-ends of the sequences were determined by comparison with previous sequences (accession nos. S82657 and S82658, and S82660 and S82661; cf. Zarlenga and Dame, 1992; Zarlenga et al., 1996).

\section{Results}

The samples of 'pooled' L1s $(n=49)$ representing the currently recognized species/genotypes of Trichinella were analysed on agarose gels. All nonencapsulated species of Trichinella, including the three distinct genotypes of T. pseudospiralis, produced ES5 amplicons ranging in size between $\sim 310$ and $450 \mathrm{bp}$. Encapsulated species related to amplicons of $\sim 270 \mathrm{bp}$ (T. spiralis and T. nelsoni) or $\sim 230 \mathrm{bp}$ (T. nativa, $T$. britovi, T. murrelli and the unclassified genotypes Trichinella T6, T8 and T9) (Fig. 1). Twenty-four unique banding patterns were identified among all the samples tested. Upon evaluating both single-stranded (ss) and double-stranded (ds) DNA, the number of bands per profile varied from $\sim 4$ to 14 . Intra-specific variation in profiles was observed among isolates representing $T$. spiralis, T. britovi and T. pseudospiralis (Fig. 1). To determine the lower level of sequence variation detectable by SSCP, ES5 from two T. spiralis isolates (codes ISS328 and ISS329) were cloned, and seven individual clones per isolate were sequenced. In addition to several single base substitutions at aligned positions, one di-nucleotide (CA; positions 163 and 164) appearing within a microsatellite repeat was detected between the two samples (not shown). The greatest intra-specific variation was displayed among $T$. pseudospiralis isolates from the Palearctic, Nearctic and Australian regions as predicted from a previous study (Zarlenga et al., 1996).

Given the high level of sequence heterogeneity within the ES5 of Trichinella (Zarlenga et al., 1996), we chose to evaluate a less variable region within domain 3 (D3) of the large subunit rDNA. As with ES5, D3 amplicons were subjected to SSCP. Significant differences in profiles were observed among most of the species/genotypes investigated; however, no substantial
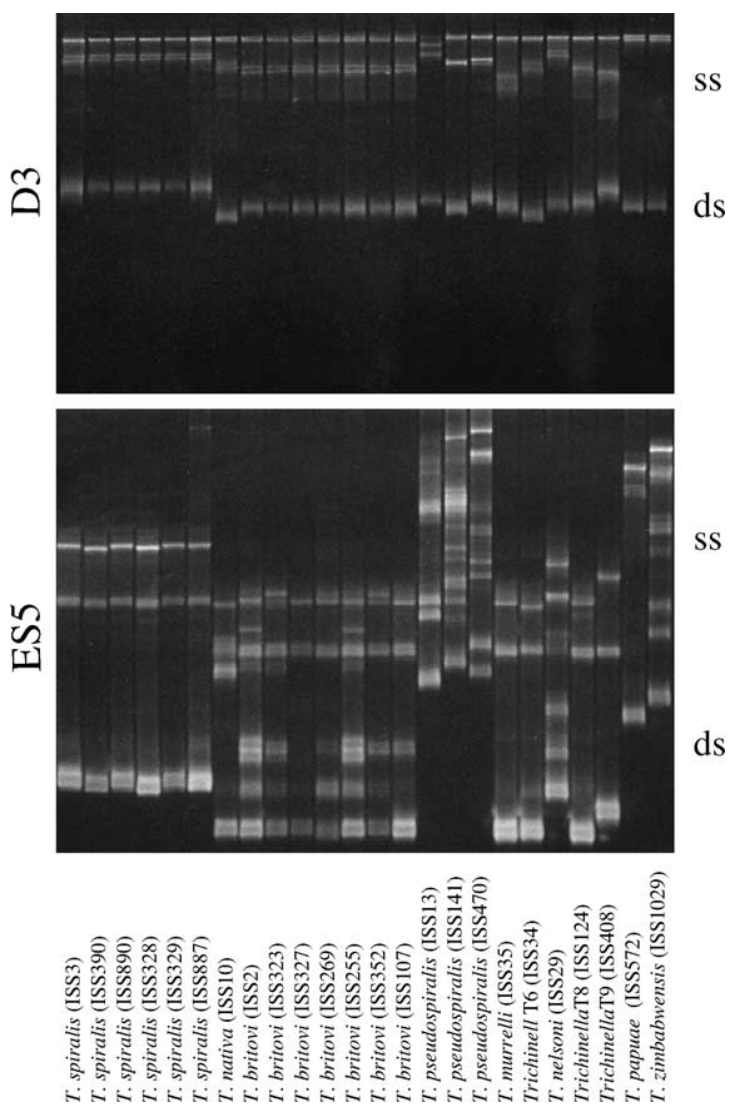

Fig. 1. Cold SSCP analysis of amplicons from the ES5 region or the D3 domain of nuclear ribosomal DNA, amplified from Trichinella gDNA samples.

intra-specific size variation was detectable. Not surprisingly, neither T. nativa and Trichinella T6 could be differentiated, nor could $T$. papuae and $T$. zimbabwensis. The D3 sequences from PCR amplified gDNA varied in length from 371 to $399 \mathrm{bp}$, with variation among species/genotypes ranging from 0 to 19.9\%. As expected based on the SSCP analysis, D3 amplicons from T. nativa and Trichinella T6 reference strains had the same sequence, as did the amplicons from T. papuae and T. zimbabwensis (data not shown). Based on these findings, D3 sequences differing by $\sim 0.3 \%$ were easily differentiated by SSCP.

\section{Discussion}

Data presented here demonstrate the applicability of cold SSCP to accurately display genetic variation 
within the genus Trichinella. Samples representing pooled L1s were employed; however, the analysis of individual L1s is readily achieved (not shown). The SSCP approach is considered simple, time- and costeffective, and can be adapted to 'high throughput' analyses ( $\sim 150$ samples in one electrophoresis run). While real-time PCR and automated, fluorescencebased slab or capillary gel electrophoretic systems represent alternatives for mutation scanning, they are presently considerably more expensive to perform than the technique presented here.

SSCP can be particularly useful for DNA loci which contain relatively high levels of intra-isolate sequence heterogeneity (such as the ES5) (cf. Zarlenga et al., 1996) and which cannot be sequenced directly. In addition, the approach can be used when sequence analysis via cloning is not able to accurately define the extent of sequence heterogeneity within and among amplicons. Selective sequencing showed that variability of as little as two nucleotides in the ES5 could be readily detected between two T. spiralis samples (codes ISS328 and ISS329). While it is possible that some of the single base alterations detected among clones could relate to artefacts produced during PCR, this is less likely for some of the transversions recorded (data not shown). For the D3 domain, no sequence heterogeneity was detectable by SSCP or sequencing within or between isolates of T. spiralis. Although it was neither possible to distinguish T. nativa from Trichinella T6 nor T. papuae from T. zimbabwensis based on the SSCP and sequence analyses of D3 amplicons, it was possible to distinguish among all of them using ES5. Nuclear ribosomal DNA loci were used herein; however, SSCP can be applied to a wide range of genetic markers to study and compare the genetic make-up of Trichinella populations, and thereby test current hypotheses regarding the systematic relationships of members within the genus.

\section{Acknowledgements}

Thanks to G. Marucci for the isolation of larvae from the musculature, to Xingquan Zhu for DNA extractions and to Neil Chilton for discussion regarding the design of primers. The sample collection and maintenance of Trichinella in laboratory animals received, in part, financial support from the project "TRICHIPORSE" of the European Union (contract QLK1-CT-2001-01156), from The University of Melbourne (Collaborative Research Program) and Elchrom Scientific AG.

\section{References}

Chilton, N.B., Huby-Chilton, F., Gasser, R.B., 2003. First complete large subunit rRNA sequence and secondary structure for a parasitic nematode-phylogenetic and diagnostic implications. Mol. Cell. Probes 17, 33-39.

Gasser, R.B., Chilton, N.B., Hoste, H., Beveridge, I., 1993. Rapid sequencing of rDNA from single worms and eggs of parasitic helminths. Nucleic Acids Res. 21, 2525-2526.

Gasser, R.B., Chilton, N.B., 2001. Applications of single-strand conformation polymorphism (SSCP) to taxonomy, diagnosis, population genetics and molecular evolution of parasitic nematodes. Vet. Parasitol. 101, 201-213.

Gasser, R.B., Zhu, X.Q., Monti, J.R., Dou, L., Cai, X., Pozio, E., 1998. PCR-SSCP of rDNA for the identification of Trichinella isolates from mainland China. Mol. Cell. Probes 12, 27-34.

Murrell, K.D., Lichtenfels, J.R., Zarlenga, D.S., Pozio, E., 2000. The systematics of the genus Trichinella with a key to species. Vet. Parasitol. 93, 293-307.

Orita, M., Iwahana, H., Kanazawa, H., Hayashi, K., Sekiya, T., 1989. Detection of polymorphisms of human DNA by gel electrophoresis as single-strand conformation polymorphism. Proc. Natl. Acad. Sci. U.S.A. 86, 2766-2770.

Pozio, E., La Rosa, G., Rossi, P., 1989. Trichinella Reference Centre. Parasitol. Today 5, 169-170.

Pozio, E., Foggin, C.M., Marucci, G., La Rosa, G., Sacchi, L., Corona, S., Rossi, P., Mukaratirwa, S., 2002. Trichinella zimbabwensis n. sp. (Nematoda), a new non-encapsulated species from crocodiles (Crocodylus niloticus) in Zimbabwe also infecting mammals. Int. J. Parasitol. 32, 1787-1799.

Zarlenga, D.S., Dame, J.B., 1992. The identification and characterization of a break within the large subunit of ribosomal RNA of Trichinella spiralis: comparison of gap sequences within the genus. Mol. Biochem. Parasitol. 51, 281-290.

Zarlenga, D.S., La Rosa, G., Pozio, E., Rosenthal, B., 2004. Identification and classification within the genus Trichinella, with special emphasis on non-encapsulated species. Vet. Parasitol. $125,75-78$.

Zarlenga, D.S., Chute, M.B., Martin, A., Kapel, C.M., 1999. A multiplex PCR for unequivocal differentiation of all encapsulated and non-encapsulated genotypes of Trichinella. Int. J. Parasitol. 29, 1859-1867.

Zarlenga, D.S., Chute, M.B., Martin, A., Kapel, C.M., 2001. A single, multiplex PCR for differentiating all species of Trichinella. Parasite 8, S24-S26.

Zarlenga, D.S., La Rosa, G., 2000. Molecular and biochemical methods for parasite differentiation within the genus Trichinella. Vet. Parasitol. 93, 279-292. 